\title{
Commercial Sex Work During Novel Coronavirus (SARS-CoV-2) Era in the Niger Delta Region: Relationships Between Knowledge, Preventive Practice, and Transmission Potential
}

\author{
Godwin Avwioro (1D) \\ Andy Egwunyenga $\mathbb{D}^{2}$ \\ Collins Adjekuko $\mathbb{1}^{3}$ \\ Osaro Mgbere iD ${ }^{4,5}$ \\ Ewomazino Odibo $\mathbb{D}^{2}$ \\ Sina lyiola $\mathbb{D D}^{6}$ \\ Seyi Samson Enitan (D) $^{7}$ \\ Ekere James Essien (iD) 4,5 \\ 'Faculty of Science, Delta State \\ University, Abraka, Nigeria; ${ }^{2}$ Department \\ of Animal and Environmental Biology, \\ Faculty of Science, Delta State University, \\ Abraka, Nigeria; ${ }^{3}$ Department of Medical \\ Laboratory Services, General Hospital, \\ Asaba, Delta State, Nigeria; ${ }^{4}$ Institute of \\ Community Health, University of \\ Houston College of Pharmacy, Houston, \\ TX, USA; ${ }^{5}$ Department of Pharmaceutical \\ Health Outcomes and Policy, University \\ of Houston College of Pharmacy, \\ Houston, TX, USA; ${ }^{6}$ Department of \\ Histopathology, Obafemi Awolowo \\ University Teaching Hospital, lle-lfe, \\ Nigeria; 'Department of Medical \\ Laboratory Science, Babcock University, \\ Ilisan-Remo, Ogun State, Nigeria
}

Background: Sex workers, like others, are facing economic hardships and anxiety about their health and safety due to coronavirus disease-2019 (COVID-19), an infectious disease caused by a novel severe acute respiratory syndrome coronavirus 2 (SARS-CoV-2). Universally, most sex work has largely reduced, moved online, or undertaken covertly because of lockdown measures and need for social distancing to break the transmission of SARS-CoV-2. However, the ability of sex workers to protect themselves against COVID-19 depends on their individual and interpersonal behaviors and work environment. In this study, we sought to determine the relationships between COVID-19 knowledge, awareness and prevention practice (KAP) among female commercial sex workers (FCSW) in the Niger Delta region of Nigeria to inform the development of prevention interventions for this vulnerable population.

Methods: Data used in this study were obtained from a cross-sectional survey of 604 FCSW operating in the Niger Delta region of Nigeria. We used descriptive and inferential statistics to assess their socio-demographic characteristics and COVID-19 KAP adopted against the novel coronavirus. Latent class analysis was used to systematically classify participants' attributes and behaviors into the most likely distinct clusters or risk groups.

Results: The majority of the FCSW were singles (86.8\%) of childbearing ages, 21-35 years $(86.2 \%)$, with almost three quarters $(73.2 \%)$ of them having sex with 3-4 clients per day during the COVID-19 pandemic. Overall, almost three quarters of the participants had both good knowledge and awareness about COVID-19 but less than half of them (41.1\%) implemented good practice to prevent the spread of the disease. However, a highly significant and positive relationship was recorded between COVID-19 knowledge $(r=0.90, p<0.0001)$ and awareness $(r=0.65, p<0.0001)$, and preventive practice of FCSW, respectively. About $89.1 \%$ of the participants were not very familiar with the symptoms of COVID-19 ( $p<0.0001)$. Only $10.9 \%$ of the FCSW indicated that they wear facemask at all times, while $45.2 \%$ of them do not wear facemask during sexual intercourse with their clients $(p<0.0001)$. Based on the FCSW attributes and behaviors, we identified three distinct clusters or risk groups ( $p<0.0001)$, namely, low-risk takers (Cluster 1), high-risk takers (Cluster 2) and very high-risk takers (Cluster 3) with latent class prevalence rates $\left(\gamma_{\mathrm{c}}\right)$ of $41.13 \%(95 \% \mathrm{CI}: 37.26-45.10), 33.17 \%(95 \% \mathrm{CI}$ : 29.53-37.02) and $25.71 \%$ (95\% CI: 22.38-29.34), respectively.

Conclusion: Sex work has high transmission potentials for SARS-CoV-2 because of its operational nature, which does not permit social distancing, and thus, renders certain preventive measures practically ineffective. This is a major challenge in the fight against COVID-19 in this high-risk group and calls for the development of operational guidelines and targeted intervention strategies to help reduce the spread of COVID-19 in the Niger Delta region.
Correspondence: Osaro Mgbere Institute of Community Health, University of Houston College of Pharmacy, Houston, TX, USA

Email omgbere@uh.edu 


\section{Introduction}

The first official case of the novel coronavirus was reported in Wuhan, China on December $31^{\text {st }}, 2019 .{ }^{1}$ To date, more than 135 million confirmed cases and approximately 2.9 million deaths have been reported worldwide. ${ }^{1}$ More than 163,793 cases and 2060 deaths have been reported in the Federal Republic of Nigeria. ${ }^{2}$ In response to the global pandemic, the Nigerian government established a Presidential Task Force for the Control of COVID-19, closed its borders, and mandated a national lockdown. ${ }^{3}$ While these measures have been effective in minimizing the spread of the disease, a consensus is emerging that the COVID-19 pandemic has caused significant disruption in the country's economic, social, and healthcare systems. $^{3-6}$ Thus, there is a need for studies that examine the socio-ecological impact of the COVID-19 pandemic in the context of a developing country such as Nigeria, and its effect on specific occupations and subgroups.

Several socio-ecological and psychological factors converge to increase the morbidity and mortality from COVID-19 infection in Nigeria. Aside from the health complications of the disease, the high reproductive number $\left(R_{o}\right)$ of the coronavirus increases its infectiousness and the efficiency of person-to-person transmission. ${ }^{7}$ In addition, poverty, misperceptions about the origin of the disease, deficiencies in the healthcare infrastructure, lack of skilled healthcare personnel, inadequate knowledge about the disease, and limited social safety nets from the government have all contributed to poor compliance with measures to prevent the spread of the disease. ${ }^{3}$ Although the factors that promote the spread of COVID-19 in Nigeria remain notably understudied, this information is necessary to guide the development of culturally tailored prevention interventions.

The Niger Delta region of Nigeria is particularly vulnerable to the spread of COVID-19 due to densely populated waterfront settlements, limited availability of healthcare services and a large informal labor sector. ${ }^{8}$ One of the groups that exemplifies the vulnerability in the informal labor sector are FCSW. In general, poverty and high level of unemployment, ${ }^{9}$ oil exploration and exploitation activities in the Niger Delta have been known to accentuate the rate of prostitution in the region, with sex for money and drugs exchanges between FCSW and employees of the oil companies. As elucidated by David et al, there is a relationship between poverty and prostitution, and rate of infectious disease transmission in the region. ${ }^{10}$ FCSW are at an increased risk of contracting COVID-19 infection as a result of criminalization, unstable housing, limited access to reproductive health care, stigmatization, drug use and various forms of personal and structural/systemic violence and abuse. ${ }^{11-14}$ All of these intersecting experiences impact sex workers' ability to access health care and limit their ability to adhere to COVID-19 prevention practices, and therefore, put them at greater risk of contracting COVID-19. ${ }^{11}$ Unfortunately, there exists no direct policies for the protection of health needs of sex workers during pandemics. ${ }^{15}$ Therefore, the financial hardship occasioned by the directive on social distancing remains a major challenge to the FCSW. Most sex workers are unable to cover the costs of food and shelter for themselves and their dependents, ${ }^{16}$ and thus, have no option but to continue working, placing their health and lives at risk. For instance, while concurrently balancing a stark decrease in clients, sex workers are forced under pressure to agree to unsafe practices that they would otherwise avoid. ${ }^{14}$

Being a clandestine business, FCSW and their clients are bound to find ways to operate despite the government's lockdown orders, which in most cases are devoid of effective enforcement and/or used by security agents to provide cover for seeking gratification in kind or cash from sex workers and operators of hotels, brothels, bars, club houses, etc. By the nature of sex work, which involves intimacy, physical distancing is impossible to practice by individuals who rely on it for income and survival. There is mounting evidence that sex workers face unique transmission risks, mental health needs and socio-economic challenges relative to COVID-19 that have largely been ignored by health organizations and governments. ${ }^{17-20}$ Consequently, FCSW may serve as a reservoir for the community transmission of SARS-CoV-2.

These socio-ecological factors create difficulties in developing health promotion programs for this group and limit the sex worker's ability to comply with COVID-19 prevention guidelines. ${ }^{21}$ However, prior work in Africa has revealed that acceptance and adherence to COVID19 prevention measures are predicated upon the 
knowledge and attitudes that people have about the disease. $^{22}$ In this study, which is the first of its kind in the Niger Delta region of Nigeria, we sought to determine the relationship between knowledge and COVID-19 prevention practices among FCSW in the region to inform the development of prevention interventions for this vulnerable population.

\section{Methods}

\section{Study Design and Population}

This study was a cross-sectional survey of FCSW operating in the Niger Delta region of Nigeria, which comprised of the following nine states namely Abia, Akwa-Ibom, Bayelsa, Cross River, Delta, Edo, Imo, Ondo and Rivers. The eligible population and criteria for this study were women who engaged in commercial sex or sexual services in exchange for money or goods, ${ }^{23}$ and consciously define those activities as income generating. A total of 604 consenting FCSW who operated within randomly selected hotels, brothels, bars and club houses in the various states in the region responded to the survey. The survey was conducted between May and July 2020 covering the period during the government mandatory lockdown and shortly after the lockdown was lifted.

\section{Study Area}

The Niger Delta region is located between latitude $4^{\circ} 15^{\prime} \mathrm{N}$ and $4^{\circ} 50^{\prime} \mathrm{N}$ and longitude $5^{\circ} 25^{\prime} \mathrm{E}$ and $7^{\circ} 37^{\prime} \mathrm{E}$. The region spans over $70,000 \mathrm{~km}^{2}$ (27,000 square miles) and it is Nigeria's largest wetland, and the third largest wetland in the world with two seasons, the wet (May-September) and dry (October-April) seasons. With a steadily growing population put at over 40 million people as of 2006, the region accounts for more than $23 \%$ of Nigeria's total population of over 140 million, and its land mass represents $12 \%$ of Nigeria's total surface area. ${ }^{24}$ The Niger Delta has been described as heterogeneous, multi-cultural and ethnically diverse region. ${ }^{25}$ There are more than 40 ethnic groups including the Annang, Ibibio, Efik, Ijaw, Urhobo, Itsekiri, Edo, Igbo and Yoruba people speaking about 250 different dialects. ${ }^{25}$ The Niger Delta is rich in oil and several decades of oil companies' activities in the area have caused huge environmental devastation in the region including related health and socio-economic problems. The lack of distribution of oil wealth has been the source and/or key aggravating factors of numerous environmental movements and inter-ethnic conflicts in the region over the years. ${ }^{26}$

\section{Study Instrument and Data Collection}

The study used a structured questionnaire to elicit responses from the FCSW and was designed following the guidelines and recommendations of Nigeria Center for Disease Control (NCDC) ${ }^{27}$ and previous literature on COVID-19 knowledge, attitude and preventive practice. $^{28-30}$ The instrument sought information on the responders' socio-demographic characteristics, average number of clienteles per day, years of experience working as FCSW, their opinion on government abolishment of commercial sex work, if they made more or less money because of COVID-19. The instrument specifically explored FCSW KAP towards COVID-19 that included their knowledge of SARS-CoV-2 transmission and prevention in relation to their clients, how informed their family members and fellow FCSW are about COVID-19 and their beliefs and disposition to the measures put in place by government to prevent the spread of the disease. We adopted two steps to validate the study instrument, first, the initial draft of the questionnaire was shared with experts in public health, medical and behavioral sciences for assessment of the contents and relevance, simplicity, ease of understanding of the items and time required to complete the questionnaire relative to the sample population of interest. Secondly, we conducted a pilot test of the instrument using a sample of 60 FCSW. Data obtained from the pilot test were analyzed and experts' opinion were sought to revise the questionnaire and make it simpler and shorter. The final validated questionnaire was administered in-person by trained research assistants or through representatives in the brothels, hotels, bars and club houses who received just-in-time training because of the uncooperative nature of some of the FCSW. The questionnaire was administered only to FCSW who consented to participate in the survey. A total of 604 FCSW responded to the survey. The research assistants who administered the questionnaire took all the necessary precautions and followed the recommended COVID-19 guidelines including wearing of facemasks and use of alcohol-based hand sanitizers during the field work.

\section{Data Management and Measures}

The FCSW responses to questions related to COVID-19 KAP were collated and scored. The measures scale varied slightly by questions and include responses that ranged 
from yes/no, to graduated responses and Likert scales, some of which applied forced choice method (Table S1). Some variables that had negatively worded questions were reverse scored. We computed the KAP scores by summing up the item scores within each subscale. The COVID-19 Knowledge subscale comprised of 8 items including knowledge of COVID-19 symptoms, prevention, disease fatality, use of facemask during sex, social distancing, spread and co-worker related COVID knowledge. The COVID-19 awareness subscale also comprised of 8 items including exposure to COVID-19 information, ever seen COVID-19 patient (through the media), where to receive treatment, phone number to call for care, family and friends' awareness of COVID-19, COVID19 work safety measures, and belief about COVID-19 community spread. The COVID-19 preventive practice subscale among FCSW comprised of 2 items including, use of face mask during sex and kissing during sexual encounter. The COVID-19 Knowledge subscale had a mean score of 16.03 (SD: 1.94, Range: 13-21) and Cronbach $\alpha$ of 0.60 , while COVID-19 awareness subscale had a mean score of 11.90 (SD: 1.57, Range: 9-14) and Cronbach $\alpha$ of 0.64 . The COVID-19 preventive practice subscale had a mean score of 3.49 (SD: 1.09, Range: 1-6) and Cronbach $\alpha$ of 0.58 . Subsequently, using the mean values, we created dichotomized categorical measures for KAP defined as "good" ( $\geq$ mean) and "poor" (< mean), respectively.

The independent factors considered in our study include: marital status (single, child outside wedlock, widowed), age group (15-20, 21-25, 26-30 and 31-35 years); habit (Alcohol, alcohol+cigarettes, alcohol+cigarettes+drugs, none); average number of sex clients per day (1-2, 3-4, 5-6 clients); years of experience as FCSW (0-1, 2-4, 5-6 years), support for government prohibition of commercial sex work $(\mathrm{No} / Y e s$, only if the government provides an alternative means of livelihood).

\section{Statistical Analysis}

We applied descriptive statistics such as frequency and percentage to evaluate the distribution of the sociodemographic characteristics of the study population. Furthermore, we carried out a univariable analysis of FCSW COVID-19 KAP-related questions to determine the independent associations of their responses using Chisquare inferential test. To qualitatively assess the FCSW overall response, we also applied the Chi-square inferential test to determine the independent associations between dichotomized measures of KAP ("good" vs "poor"). To determine the internal consistency and reliability of the items used to compute the KAP scores, we applied the Cronbach's alpha coefficient and obtained a fair to good internal consistency for the three measures. Following this, a series of bivariate analyses that include $t$-test or one-way analysis of variance were conducted, as applicable, to compare differences in computed scores of COVID-19 knowledge, awareness, and preventive practices of FCSW by socio-demographic characteristics. To examine the direct relationships between COVID-19 knowledge, awareness and preventive practice scores, we carried out bivariate curve fitting using different models with the goal of defining the "best fit" model and density contour mapping was used to determine potential patterns (clusters) within the measures. Density ellipse probability was applied to evaluate the mass of points of the measures at $p=0.25, p=0.50$ and $p=0.75$. The bivariate fit models produced equations that described the relationships between the measures. Additionally, we used Pearson's correlation coefficient to determine the linear correlation between KAP scores.

Following the study population heterogeneity with respect to a set of manifest variables, we used the Latent Class Analysis (LCA) to systematically classify respondents' attributes and behaviors into the most likely distinct clusters or latent classes (homogeneous subgroups) with a given trait that is not directly observed (manifest). ${ }^{31}$ The LCA produced the latent class prevalences $\left(\gamma_{c}\right)$ and the conditional probabilities $(\rho)$ for each cluster and response category. The $\gamma_{\mathrm{c}}$ and $\rho$ parameters for latent class models were estimated using the iterative ExpectationMaximization (EM) algorithm. ${ }^{32}$ Estimates of the effect size and Likelihood Ratio Logworth (LR Logworth) obtained from a contingency table analysis of expected counts for cluster membership by levels or categories of a Y column were used to quantify differences within the response scales. The fit statistics of negative log-likelihood (-Log-Likelihood), Bayesian Information Criterion (BIC), and Akaike's Information Criterion (AIC) were used to compare the clusters with the smallest values of each indicating the best fit. All statistical tests conducted were 2-tailed, and probability of $\leq 0.05$ was used as the threshold for declaring statistical significance. Data management and statistical analyses were conducted using SAS JMP Statistical Discovery $^{\text {TM }}$ Software version 14.3 (SAS Institute, Cary, North Carolina, USA). 


\section{Human Subject Protection}

This study protocol and materials were reviewed and approved by the Research and Ethics Committee of the Delta State University, Abraka, Delta State, Nigeria (REC/FOS/DEL/20/ 18 of 4th May 2020). Informed consents were obtained from all FCSW who participated in the survey. For participants under the age of 18 years, informed consents were obtained from their parent or guardian prior to enrollment. All participants were informed of the purpose of the study and the fact that participation in the survey was anonymous, consensual, and voluntary. The research team complied with all ethical principles and codes of conduct set forth in the Declaration of Helsinki.

\section{Results}

\section{Characteristics of the Study Population}

Table 1 shows the socio-demographic characteristics of the study population. The majority of the FCSW were single (86.8\%), $1.2 \%$ were widows, and about $12.1 \%$ of them had children outside of wedlock. About $86.2 \%(\mathrm{n}=522)$ of the FCSW were of childbearing age, 21-35 years. One-third of the participants $(33.1 \%)$ were between the ages $26-30$ years. Also, almost three quarters $(73.2 \%)$ of the participants had sex with 3-4 persons per day. Around $41.4 \%$ of the participants have been operating as FCSW for 2-4 years, while $32.9 \%$ have been operating for 5-6 years. Meanwhile, more than half of the participants (66.4\%) declared that they would be happy if government prohibits commercial sex business provided government is willing to provide an alternative means of livelihood for them.

\section{COVID-19 Knowledge, Awareness and Preventive Practice Scores by Socio-Demographic Characteristics}

The comparisons of the FCSW COVID-19 KAP scores by socio-demographic characteristics is presented in Table 2. The overall KAP mean scores were $16.03 \pm 0.08,11.90$ \pm 0.06 and $3.49 \pm 0.04$, respectively. We noted highly significant variations across these measures by socio-demographic characteristics of FCSW in the Niger Delta region. For instance, COVID-19 knowledge among FCSW improved significantly $(p<0.0001)$ with age from 14.00 \pm 0.19 ( $15-20$ years) to $17.32 \pm 0.14$ ( $31-35$ years) and individuals who engaged in the habit of drinking alcohol, smoking and using drugs were significantly $(p<0.0001)$ more knowledgeable about COVID-19 than those that do not indulge in these habits. Participants who had 2-4
Table I Socio-Demographic Characteristics of Study Participants

\begin{tabular}{|c|c|c|}
\hline Characteristic & $\mathbf{N}$ & $(\%)^{a}$ \\
\hline \multicolumn{3}{|l|}{ Marital status } \\
\hline Single & 524 & 86.8 \\
\hline Widowed & 7 & 1.2 \\
\hline Child outside of wedlock & 73 & I2.I \\
\hline \multicolumn{3}{|l|}{ Age (Years) } \\
\hline $15-20$ & 82 & 13.6 \\
\hline $2 I-25$ & 183 & 30.3 \\
\hline $26-30$ & 200 & 33.1 \\
\hline $31-35$ & 139 & 23.0 \\
\hline \multicolumn{3}{|l|}{ Habit } \\
\hline Alcohol & 243 & 40.3 \\
\hline Alcohol + Cigarettes & 246 & 40.8 \\
\hline Alcohol + Cigarettes + Drugs & 32 & 5.3 \\
\hline None & 82 & 13.6 \\
\hline \multicolumn{3}{|l|}{ Average number of sex clients per day } \\
\hline $1-2$ & 89 & 14.7 \\
\hline $3-4$ & 442 & 73.2 \\
\hline $5-6$ & 73 & 12.1 \\
\hline \multicolumn{3}{|l|}{ Years of experience as a FCSW } \\
\hline $0-1$ & 155 & 25.7 \\
\hline $2-4$ & 250 & 41.4 \\
\hline $5-6$ & 199 & 32.9 \\
\hline \multicolumn{3}{|l|}{$\begin{array}{l}\text { Support for Government Prohibition of } \\
\text { Commercial Sex Work }\end{array}$} \\
\hline Yes $^{\mathrm{b}}$ & 401 & 66.4 \\
\hline No & 203 & 33.6 \\
\hline
\end{tabular}

Notes: ${ }^{a}$ Within characteristic, percentages may not add up to exactly 100 due to rounding up. ${ }^{b}$ Only if the government provides an alternative means of livelihood.

years' experience in providing sexual services had significantly $(p<0.0001)$ better COVID-19 knowledge $(17.30$ $\pm 0.09)$ than those that had engaged in sex work for less than a year $(14.00 \pm 0.12)$.

Awareness about COVID-19 management was significantly $(\mathrm{p}<0.001)$ below average for FCSW who were single compared to those who were widowed $(12.43 \pm 0.57)$ or had

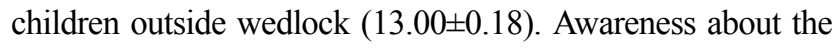
disease tended to increase significantly $(\mathrm{p}<0.0001)$ with age with FCSW who were of age group 26-30 years being most aware and conscious of their safety than others. FCSW who indulged in drinking alcohol only $(13.24 \pm 0.04)$ and those who took alcohol, cigarettes, and drugs $(12.69 \pm 0.12)$ had more than average level of awareness compared to those who did not engage in these habits $(p<0.0001)$. Participants who had sexual encounters with 1-2 and 5-6 persons daily were significantly 
Table 2 Comparisons of COVID-19 KAP by Socio-Demographic Characteristics Among FCSW in Niger Delta Region of Nigeria

\begin{tabular}{|c|c|c|c|c|c|c|c|c|c|c|}
\hline \multirow[t]{2}{*}{ Characteristic } & \multirow[t]{2}{*}{$\mathbf{N}$} & \multicolumn{3}{|c|}{ Knowledge Score } & \multicolumn{3}{|c|}{ Awareness Score } & \multicolumn{3}{|c|}{ Preventive Practice Score } \\
\hline & & Mean \pm SEM & $\begin{array}{c}\text { Prob }>1 \\
t \mid / F\end{array}$ & P-value & Mean \pm SEM & $\begin{array}{c}\text { Prob }>1 \\
\text { t//F }\end{array}$ & P-value & Mean \pm SEM & $\begin{array}{c}\text { Prob }>1 \\
t \mid / F\end{array}$ & P-value \\
\hline Overall & 604 & $16.03 \pm 0.08$ & - & - & $11.90 \pm 0.06$ & - & - & $3.49 \pm 0.04$ & - & - \\
\hline $\begin{array}{l}\text { Marital status } \\
\text { Single } \\
\text { Widowed } \\
\text { Child outside } \\
\text { wedlock }\end{array}$ & $\begin{array}{c}524 \\
7 \\
73\end{array}$ & $\begin{array}{l}16.02 \pm 0.09 \\
16.43 \pm 0.74 \\
16.02 \pm 0.09\end{array}$ & 0.1563 & $0.8554^{\mathrm{ns}}$ & $\begin{array}{c}11.74 \pm 0.07^{\mathrm{a}} \\
12.43 \pm 0.57^{\mathrm{a}, \mathrm{b}} \\
13.00 \pm 0.18^{\mathrm{b}}\end{array}$ & 22.59 & $<0.0001 * * * * *$ & $\begin{array}{c}3.56 \pm 0.0^{\mathrm{a}} \\
3.7 \mathrm{I} \pm 0.4 \mathrm{I}^{\mathrm{a}, \mathrm{b}} \\
3.00 \pm 0.13^{\mathrm{b}}\end{array}$ & 8.68 & $0.0002 * * *$ \\
\hline $\begin{array}{l}\text { Age (Years) } \\
15-20 \\
21-25 \\
26-30 \\
31-35\end{array}$ & $\begin{array}{c}82 \\
183 \\
200 \\
139\end{array}$ & $\begin{array}{l}14.00 \pm 0.19^{\mathrm{a}} \\
15.98 \pm 0.12^{\mathrm{b}} \\
16.00 \pm 0.12^{\mathrm{b}} \\
17.32 \pm 0.14^{\mathrm{c}}\end{array}$ & 66.87 & $<0.0001 * * * *$ & $\begin{array}{c}9.00 \pm 0.11^{\mathrm{a}} \\
12.00 \pm 0.07^{\mathrm{b}} \\
13.00 \pm 0.08^{\mathrm{c}} \\
11.90 \pm 0.08^{\mathrm{b}}\end{array}$ & 335.23 & $<0.0001 * * * * *$ & $\begin{array}{c}2.00 \pm 0.08^{\mathrm{a}} \\
3.98 \pm 0.05^{\mathrm{b}} \\
3.00 \pm 0.05^{\mathrm{c}} \\
4.42 \pm 0.06^{\mathrm{d}}\end{array}$ & 246.82 & $<0.0001 * * * *$ \\
\hline $\begin{array}{l}\text { Habit } \\
\text { Alcohol } \\
\text { Alcohol + Cigarettes } \\
\text { Alcohol + Cigarettes } \\
+ \text { Drugs } \\
\text { None }\end{array}$ & $\begin{array}{c}243 \\
246 \\
32 \\
\\
82\end{array}$ & $\begin{array}{l}17.24 \pm 0.10^{a} \\
15.43 \pm 0.10^{b} \\
16.59 \pm 0.28^{b} \\
14.00 \pm 0.17^{c}\end{array}$ & 106.18 & $<0.0001 * * * *$ & $\begin{array}{l}13.24 \pm 0.04^{\mathrm{a}} \\
11.43 \pm 0.04^{\mathrm{b}} \\
12.69 \pm 0.12^{\mathrm{c}} \\
9.00 \pm 0.08^{\mathrm{d}}\end{array}$ & 845.26 & $<0.0001 * * * *$ & $\begin{array}{l}3.74 \pm 0.06^{\mathrm{a}} \\
3.72 \pm 0.06^{\mathrm{a}} \\
3.66 \pm 0.16^{\mathrm{a}} \\
2.00 \pm 0.10^{\mathrm{b}}\end{array}$ & 83.43 & $<0.000 I^{* * * * *}$ \\
\hline $\begin{array}{l}\text { Average number } \\
\text { of sex clients } \\
\text { per day } \\
1-2 \\
3-4 \\
5-6\end{array}$ & $\begin{array}{c}89 \\
442 \\
73\end{array}$ & $\begin{array}{l}15.99 \pm 0.21 \\
16.04 \pm 0.09 \\
15.96 \pm 0.35\end{array}$ & 0.08 & $0.9220^{\mathrm{ns}}$ & $\begin{array}{l}12.99 \pm 0.15^{\mathrm{a}} \\
11.50 \pm 0.07^{\mathrm{b}} \\
12.99 \pm 0.17^{\mathrm{a}}\end{array}$ & 64.39 & $<0.000 I^{* * * * * *}$ & $\begin{array}{l}3.00 \pm 0.11^{\mathrm{a}} \\
3.67 \pm 0.05^{\mathrm{b}} \\
2.97 \pm 0.12^{\mathrm{a}}\end{array}$ & 25.42 & $<0.0001^{* * * * *}$ \\
\hline $\begin{array}{l}\text { Years of } \\
\text { experience as a } \\
\text { FCSW } \\
0-1 \\
2-4 \\
5-6\end{array}$ & $\begin{array}{l}155 \\
250 \\
199\end{array}$ & $\begin{array}{l}14.00 \pm 0.12^{\mathrm{a}} \\
17.30 \pm 0.09^{\mathrm{b}} \\
16.00 \pm 0.10^{\mathrm{c}}\end{array}$ & 254.21 & $<0.000$ I***** & $\begin{array}{c}9.47 \pm 0.05^{\mathrm{a}} \\
12.53 \pm 0.04^{\mathrm{b}} \\
13.00 \pm 0.04^{\mathrm{c}}\end{array}$ & 1617.71 & $<0.0001 * * * * *$ & $\begin{array}{l}2.47 \pm 0.05^{a} \\
4.51 \pm 0.04^{b} \\
3.00 \pm 0.05^{c}\end{array}$ & 571.43 & $<0.0001^{* * * * *}$ \\
\hline $\begin{array}{l}\text { Support for } \\
\text { Government } \\
\text { Prohibition of } \\
\text { Commercial Sex } \\
\text { Work } \\
\text { No } \\
\text { Yes }^{+}\end{array}$ & $\begin{array}{l}203 \\
401\end{array}$ & $\begin{array}{l}16.00 \pm 0.14 \\
16.04 \pm 0.10\end{array}$ & 0.282 & $0.7778^{\text {ns }}$ & $\begin{array}{l}12.53 \pm 0.50^{\mathrm{a}} \\
11.58 \pm 0.09^{\mathrm{b}}\end{array}$ & -7.35 & $<0.0001 * * * *$ & $\begin{array}{l}3.46 \pm 0.08 \\
3.50 \pm 0.05\end{array}$ & 0.432 & $0.6653^{\mathrm{ns}}$ \\
\hline
\end{tabular}

Notes: ${ }^{+}$Only if the government provides an alternative means of livelihood. Within each measure by characteristic, means \pm SEM with different superscripts $\left({ }^{a}\right.$, b, $\left.c\right)$ are significantly different at $p<0.05$. Significance Level: $* * * * *<0.0001 ;{ }^{\text {ns }}$ Not significant $(p>0.05)$.

Abbreviations: SEM, standard error of mean; Prob $>|t| / F$, Probability of $t$ and $F$ values.

$(p<0.0001)$ more aware of how to manage the disease than their counterparts who had 3-4 sex clients per day. The level of awareness of the COVID-19 outbreak increased significantly $(p<0.0001)$ with years of experience in sex work. FCSW who had 0-1 year experience in the business had poor level of awareness $(p<0.0001)$ about COVID-19 $(9.47 \pm 0.05)$ than those who had 5-6 years' experience (13.00 \pm 0.04$)$. Participants who do not support government prohibition of commercial sex work had above average level of awareness about the disease $(12.53 \pm 0.50, p<0.0001)$ compared to those 
that supported government prohibition of the business, if an alternative means of livelihood is provided (11.58 \pm 0.09 , $p<0.0001)$.

COVID-19 preventive practices varied significantly $(p<0.0001)$ by marital status, age group, habit, number of sex clients per day and years of experience in commercial sex work. Participants who indulged in some habits such as drinking alcohol, smoking cigarettes, and taking drugs had significantly $(\mathrm{p}<0.0001)$ better COVID-19 preventive practices than those that had no such habits. Only FCSW who had sex with 3-4 clients per day engaged in good COVID-19 preventive practices that include not kissing their clients during sexual encounter. FCSW who had 2-4 years' experience in sex work significantly $(p<0.0001)$ adopted better COVID-19 preventive practices (4.51 \pm 0.04 ) compared to others who adopted less than average preventive measures.

\section{Relationships Between COVID-19 Knowledge, and Awareness, and Preventive Practice Scores}

Figures 1-3 depict the bivariate fits and density contours showing relationships between COVID-19 KAP scores, and between awareness and knowledge scores among FCSW in the Niger Delta Region of Nigeria. The contours within the figures indicate the density of the participants relative to these measures, while the band represents the confidence intervals of predicted

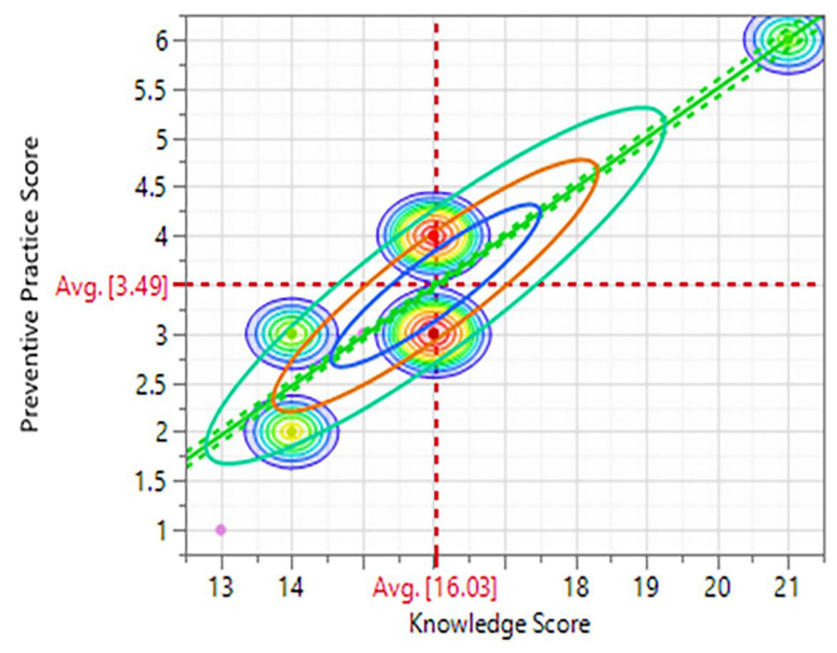

Figure I Bivariate fit and density contours showing the relationship between knowledge and preventive practice scores among FCSW in the Niger Delta Region of Nigeria.

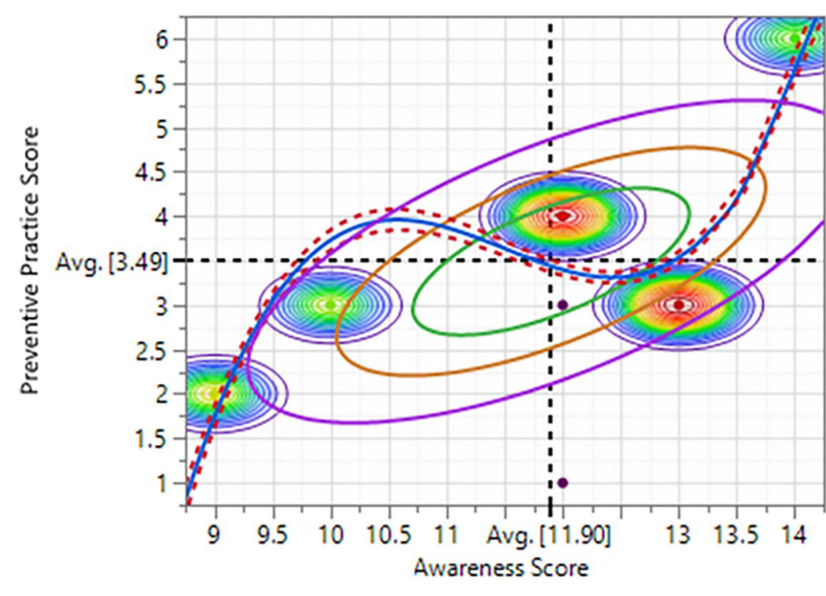

Figure 2 Bivariate fit and density contours showing the relationship between awareness and preventive practice scores among FCSW in the Niger Delta Region of Nigeria.

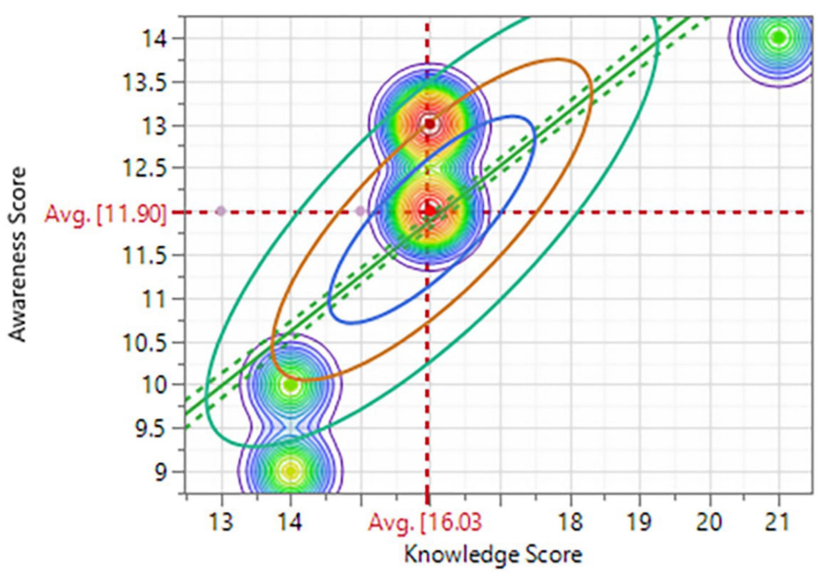

Figure 3 Bivariate fit and density contours showing the relationship between awareness and knowledge scores among FCSW in the Niger Delta Region of Nigeria.

estimates. COVID-19 preventive practice implementation among FCSW was significantly associated with their level of knowledge of the disease (Figure 1, correlation $(\mathrm{r})=0.901, p<0.0001)$, resulting in 5 distinct clusters. In contrast, the relationship between their awareness about COVID-19 management and the actual preventive practices implemented by FCSW was best fitted with a cubic curve as shown in Figure $2(\mathrm{r}=0.651, p<0.0001)$ and resulted in the identification of 5 clusters. Similarly, the relationship between awareness and knowledge score was significant and positively correlated $(\mathrm{r}=0.785, p<0.0001)$ and resulted 
in the identification of 3 main clusters (Figure 3 ). The pair-wise correlation and predictive models' equations of KAP measures are presented in Table 3. COVID-19 preventive practice was significantly $(p<0.0001)$ predicted by FCSW knowledge of the disease [Preventive Practice Score $=-4.610+0.505 \mathrm{x}$ Knowledge Score; coefficient of determination $\left(\mathrm{R}^{2}\right)$ $=81.2 \% ; p<0.0001]$, and Awareness of the disease presence [Preventive Practice Score $=8.547-0.429 \mathrm{x}$ Awareness Score +0.244 x (Awareness Score-11.899) $\wedge 2+0.205 \times\left(\right.$ Awareness Score-11.899)^3; $\mathrm{R}^{2}=73.7 \%$; $p<0.0001]$. On the other hand, awareness surrounding COVID-19 among this group in the region was determined by their level of COVID-19 knowledge
[Awareness Score $=1.7356485+0.6341599 \mathrm{x}$ Knowledge Score; $\left.\mathrm{R}^{2}=61.6 \% ; p<0.0001\right]$.

\section{Associations Between COVID-19} Knowledge, Awareness, and Preventive

\section{Practice}

The overall associations between dichotomized measure of COVID-19 KAP of FCSW are presented in Table 4. Overall, almost three quarters of the participants had both good knowledge and awareness about COVID-19 but less than half of them (41.1\%) implemented good practice to prevent the spread of the disease. We found significant association $(\mathrm{p}<0.0001)$ between the FCSW knowledge of COVID-19 and their adoption of preven-

Table 3 Pair-Wise Correlation and Predictive Models' Equations of KAP Measures Among FCSW in the Niger Delta Region of Nigeria

\begin{tabular}{|c|c|c|c|c|c|c|}
\hline Variable & $\begin{array}{l}\text { By } \\
\text { Variable }\end{array}$ & $\begin{array}{c}\text { Correlation } \\
\text { (r) }\end{array}$ & $95 \% \mathrm{Cl}$ & Model Equation & $\begin{array}{l}\mathbf{R}^{2} \\
(\%)\end{array}$ & $P$-value \\
\hline $\begin{array}{l}\text { Preventive } \\
\text { Practice Score }\end{array}$ & $\begin{array}{l}\text { Knowledge } \\
\text { Score }\end{array}$ & 0.901 & $0.885-0.915$ & $\begin{array}{l}\text { Preventive Practice Score }=-4.610+0.505 \times \text { Knowledge } \\
\text { Score }\end{array}$ & 81.2 & $<0.0001 * * * *$ \\
\hline $\begin{array}{l}\text { Preventive } \\
\text { Practice Score }\end{array}$ & $\begin{array}{l}\text { Awareness } \\
\text { Score }\end{array}$ & 0.651 & $0.602-0.695$ & $\begin{array}{l}\text { Preventive Practice Score }=8.547-0.429 \times \text { Awareness } \\
\text { Score }+0.244 \times\left(\text { Awareness Score- } 1 \text { I.899) }{ }^{\wedge}+0.205 \times\right. \\
(\text { Awareness Score-II.899) } \wedge 3\end{array}$ & 73.7 & $<0.0001 * * * *$ \\
\hline $\begin{array}{l}\text { Awareness } \\
\text { Score }\end{array}$ & $\begin{array}{l}\text { Knowledge } \\
\text { Score }\end{array}$ & 0.785 & $0.753-0.814$ & $\begin{array}{l}\text { Awareness Score }=1.7356485+0.6341599 \times \text { Knowledge } \\
\text { Score }\end{array}$ & 61.6 & $<0.0001 * * * *$ \\
\hline
\end{tabular}

Note: Significance Level: **** $\mathrm{p}<0.000$ I.

Abbreviation: $r$, correlation value; $\mathrm{Cl}$, confidence interval; $\mathrm{R}^{2}$, coefficient of determination.

Table 4 Associations Between COVID-19 KAP Among FCSW in Niger Delta, Nigeria

\begin{tabular}{|l|c|c|c|c|}
\hline \multirow{2}{*}{ Measure } & \multirow{2}{*}{ Total n (\%) } & Preventive Practice & Fisher's Exact Test \\
\cline { 2 - 5 } & & Poor & Good & P-value \\
\hline Knowledge & $157(25.99)$ & $157(25.99)$ & $0(0.00)$ & $<0.000 I^{* * * * *}$ \\
Poor & $447(74.01)$ & $199(32.95)$ & $248(4 I .06)$ & \\
Good & $156(25.83)$ & $156(25.83)$ & $0(0.00)$ & $<0.000 I^{* * * * *}$ \\
\hline Awareness & $448(74.17)$ & $200(33.11)$ & $248(41.06)$ & $248(41.06)$ \\
Poor & $604(100)$ & $356(58.94)$ & & \\
\hline Good & & & \\
\hline
\end{tabular}

Note: Significance Level: $* * * * p<0.0001$. 
tive practices. Similarly, their level of awareness about the disease management was also significantly $(\mathrm{p}<0.0001)$ associated with their preventive practices. None of the participants whose knowledge and awareness were designated as poor implemented any good preventive practice to avoid the spread of COVID-19.

\section{Univariable Analysis of KAP Items}

A summary of the univariable analysis of the items under COVID-19 KAP among FCSW in the Niger Delta region of Nigeria are presented in Table S1. Hundred percent $(100 \%)$ of the study participants stated that they have heard of COVID-19. Despite this, most of them $(89.1 \%)$ indicated that they are not familiar with

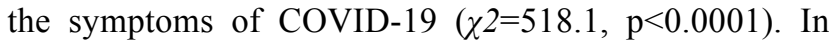
addition, $44.7 \% \quad\left(\chi^{2}=9.56, p<0.0001\right)$ of the FCSW revealed that they do not know the hospital to go to or the phone number to call for medical attention and testing $(56 \%)\left(\chi^{2}=8.58, p<0.01\right)$, if they were to contract COVID-19. Only about two-third (63.4\%) of the FCSW in the region believed that there is COVID-19 in their state of operation $\left(\chi^{2}=265.6, \quad p<0.0001\right)$. Notwithstanding the risky nature of commercial sex work, only about a third (33.3\%) of the participants believed that they could prevent the spread of the virus, if they wear facemask during sexual encounter with their clients $\left(\chi^{2}=28.4, p<0.0001\right)$. In contrast, $58.9 \%$ of the FCSW did not believe that they could infect their customers if they do not wear facemask during sexual encounters $\left(\chi^{2}=211.6, \quad p<0.0001\right)$. Similarly, $46.9 \%$ believed that their co-workers do not know that others could be infected with COVID-19, if they do not use facemask during sex with their partners $\left(\chi^{2}=138.4, p<0.0001\right)$. This result reflected the fact that as much as $58.8 \%$ of the FCSW did not encourage their co-workers to wear facemask during sex $\left(\chi^{2}=18.6\right.$, $p<0.0001)$. Although all participants (100\%) agreed that the distance between them and their clients during sexual encounter is less than $10 \mathrm{~cm}$, only $10.9 \%$ of the FCSW indicated that they wear facemask at all times and $45.2 \%$ of them do not wear facemask during sexual encounter with their clients $\left(\chi^{2}=183.4, p<0.0001\right)$. More than two-third of the FCSW (67\%) disagree/strongly disagree that they can spread COVID-19 to their customers even when they wear facemask $\left(\chi^{2}=143.3\right.$, $p<0.0001)$. About $56.2 \%$ of the FCSW indicated that they do not kiss their clients because of COVID-19 outbreak, while $13.6 \%$ of them still kissed their clients occasionally $\left(\chi^{2}=167.0, p<0.0001\right)$.

\section{Latent Class Model}

Table 5 displays the latent class prevalences $\left(\gamma_{\mathrm{c}}\right)$, the conditional probabilities $(\rho)$ for each cluster and response category, and the effect size and LR LogWorth estimates from the Latent Class analysis. Our analysis identified three significantly $(\mathrm{p}<0.0001)$ distinct most likely clusters or latent classes (homogeneous subgroups or segments) of individuals. These clusters were classified as Custer 1 (low-risk takers), cluster 2 (high-risk takers) and cluster 3 (Very highrisk takers) with latent class prevalence rates $\left(\gamma_{\mathrm{c}}\right)$ of 41.13\% (95\% CI: 37.26-45.10), 33.17\% (95\% CI: 29.53-37.02) and 25.71\% (95\% CI: 22.38-29.34), respectively. The key characteristics of the low-risk takers $(41.1 \%)$ include good COVID-19 knowledge ( $\rho=0.9993)$, good awareness $(\rho=0.9993)$, were mainly singles $(\rho=0.9870)$, of age $21-25$ years old $(\rho=0.7332)$, alcohol drinkers and cigarette smokers $(\rho=0.7091)$, have sex with 3-4 clients per day $(\rho=0.9991)$ and have been in commercial sex business for 2-4 years and have open mind on government prohibition of commercial sex business. Among the FCSW characterized as high-risk takers $(33.2 \%)$, the majority have good knowledge of COVID-19 $(\rho=0.9892)$ and are aware and abreast of the disease management $(\rho=0.9942)$ but failed to implement adequate preventive practices $(\rho=0.9992)$, most, being singles $(\rho=0.6245)$, of age group 26-30 years, alcohol drinkers $(\rho=0.9089)$, with 5-6 years' experience in commercial sex work $(\rho=0.9889)$ and have strong opposition to government prohibition of commercial sex business $(\rho=0.5399)$. On the other hand, almost $100 \%$ of FCSW designated as very high-risk takers (25.7\%) had poor COVID-19 knowledge $(\rho=0.9989)$, poor awareness $(\rho=0.9989)$ and poor implementation of recommended preventive practices $(\rho=0.9989)$. Individuals in this cluster were mainly singles $(\rho=0.9921)$ of age group $15-20$ years $(\rho=0.5284)$ or $31-35$ years $(\rho=0.4705)$, drinkers and smokers $(\rho=0.4512)$ or non-drinkers or smokers ( $\rho=0.5284)$, who have sexual encounters with 3-4 clients per day $(\rho=0.9986)$ and have $0-1$ year experience ( $\rho=0.9986)$ in delivering sexual services and are open to government prohibition of commercial sex work if alternative means of livelihood is provided $(\rho=0.9989)$. 
Table 5 Latent Class Model Conditional Probabilities of Responses to KAP Measures and Socio-demographic Characteristics of FCSW in the Niger Delta Region of Nigeria

\begin{tabular}{|c|c|c|c|c|c|c|c|}
\hline \multirow[t]{2}{*}{ Measure/Characteristic } & \multirow{2}{*}{$\begin{array}{l}\text { Categoryl } \\
\text { Response Scale }\end{array}$} & \multirow[t]{2}{*}{$\mathbf{N}$} & \multicolumn{3}{|c|}{ Distribution of Latent Classes ${ }^{a}$} & \multirow[t]{2}{*}{ Effect Size $^{b}$} & \multirow{2}{*}{$\begin{array}{c}\text { LR } \\
\text { Logworth }\end{array}$} \\
\hline & & & $\begin{array}{l}\text { Cluster I } \\
\text { [Low Risk] }\end{array}$ & $\begin{array}{c}\text { Cluster } 2 \\
\text { [High Risk] }\end{array}$ & $\begin{array}{c}\text { Cluster } 3 \text { [Very } \\
\text { High Risk] }\end{array}$ & & \\
\hline Overall & $\gamma_{c}$ & 604 & $(41.12 \%)$ & $(33.17 \%)$ & $(25.71 \%)$ & - & - \\
\hline \multirow[t]{2}{*}{ Knowledge } & Poor & 157 & 0.0007 & 0.0108 & 0.9989 & \multirow[t]{2}{*}{$0.9893(\mathrm{~L})$} & \multirow[t]{2}{*}{143.89} \\
\hline & Good & 447 & 0.9993 & 0.9892 & 0.0011 & & \\
\hline \multirow[t]{2}{*}{ Awareness } & Poor & 156 & 0.0007 & 0.0058 & 0.9989 & \multirow[t]{2}{*}{$0.9935(\mathrm{~L})$} & \multirow[t]{2}{*}{145.52} \\
\hline & Good & 448 & 0.9993 & 0.9942 & 0.0011 & & \\
\hline \multirow[t]{2}{*}{ Preventive Practice } & Poor & 356 & 0.0007 & 0.9992 & 0.9989 & \multirow[t]{2}{*}{$0.9983(\mathrm{~L})$} & \multirow[t]{2}{*}{175.65} \\
\hline & Good & 248 & 0.9993 & 0.0008 & 0.0011 & & \\
\hline \multirow[t]{3}{*}{ Marital Status } & $\begin{array}{l}\text { Child Outside } \\
\text { Wedlock }\end{array}$ & 73 & 0.0004 & 0.3599 & 0.0007 & \multirow[t]{3}{*}{$0.5233(\mathrm{M})$} & \multirow[t]{3}{*}{36.755} \\
\hline & Single & 524 & 0.9870 & 0.6245 & 0.9921 & & \\
\hline & Widowed & 7 & 0.0125 & 0.0155 & 0.0072 & & \\
\hline \multirow[t]{4}{*}{ Age Group (Years) } & $15-20$ & 82 & 0.0003 & 0.0004 & 0.5284 & \multirow[t]{4}{*}{$1.2736(\mathrm{~L})$} & \multirow[t]{4}{*}{231.38} \\
\hline & $21-25$ & 183 & 0.7332 & 0.0054 & 0.0005 & & \\
\hline & $26-30$ & 200 & 0.0003 & 0.9938 & 0.0005 & & \\
\hline & $31-35$ & 139 & 0.2661 & 0.0004 & 0.4705 & & \\
\hline \multirow[t]{4}{*}{ Habit } & Alcohol & 243 & 0.2460 & 0.9089 & 0.0005 & \multirow[t]{4}{*}{$0.9863(\mathrm{~L})$} & \multirow[t]{4}{*}{141.04} \\
\hline & $\begin{array}{l}\text { Alcohol + } \\
\text { Cigarettes }\end{array}$ & 246 & 0.7091 & 0.0004 & 0.4512 & & \\
\hline & $\begin{array}{l}\text { Alcohol + } \\
\text { Cigarettes + Drugs }\end{array}$ & 32 & 0.0446 & 0.0903 & 0.0198 & & \\
\hline & None & 82 & 0.0003 & 0.0004 & 0.5284 & & \\
\hline \multirow[t]{3}{*}{ Average number of sex clients per day } & $1-2$ & 89 & 0.0004 & 0.4398 & 0.0007 & \multirow[t]{3}{*}{$0.8546(\mathrm{~L})$} & \multirow[t]{3}{*}{105.35} \\
\hline & $3-4$ & 442 & 0.9991 & 0.1952 & 0.9986 & & \\
\hline & $5-6$ & 73 & 0.0005 & 0.3650 & 0.0007 & & \\
\hline \multirow[t]{3}{*}{ Years of experience as a FCSW } & $0-1$ & 155 & 0.0004 & 0.0006 & 0.9986 & \multirow[t]{3}{*}{1.4054 (L) } & \multirow[t]{3}{*}{272.88} \\
\hline & $2-4$ & 250 & 0.9991 & 0.0105 & 0.0007 & & \\
\hline & $5-6$ & 199 & 0.0005 & 0.9889 & 0.0007 & & \\
\hline \multirow{2}{*}{$\begin{array}{l}\text { Support for Government Prohibition of } \\
\text { Commercial Sex Work }\end{array}$} & No & 203 & 0.3792 & 0.5399 & 0.0011 & $0.4413(\mathrm{M})$ & 35.079 \\
\hline & Yes $^{d}$ & 401 & 0.6208 & 0.4601 & 0.9989 & & \\
\hline $\begin{array}{l}\text { Model Fit Statistics }[\text { Number of } \\
\text { Cluster=3] }\end{array}$ & Best fit estimates & & - LogLikeliho & $=1980.60 ; \mathrm{BIC}=$ & $81.29 ; \mathrm{AIC}=4061.19$ & mallest $\mathrm{BIC}$ and & $\mathrm{AIC}]$ \\
\hline
\end{tabular}

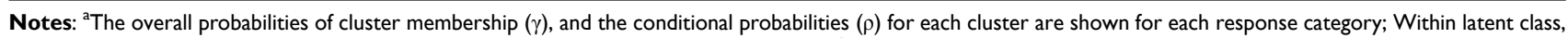
bold $\rho$ denotes the largest conditional probability within a given measure or characteristic. ${ }^{b} \mathrm{M}=$ Medium effect; $L=$ Large effect. ${ }^{\mathrm{C}} \mathrm{A}$ Likelihood Ratio Logworth value above 2 corresponds to significance at the 0.01 significance level $(\mathrm{p}<0.0 \mathrm{I})$. ${ }^{\mathrm{d}}$ Only if the government provides an alternative means of livelihood. ${ }^{\mathrm{e}} \mathrm{BIC}=\mathrm{Bayesian}$ Information $\mathrm{Criterion}$, AIC=Akaike's Information Criterion. 


\section{Discussion}

Since the declaration of Coronavirus disease (COVID-19) by World Health Organization as a pandemic, ${ }^{33}$ it has resulted in massive global health challenges that require significant behavior change with resultant psychological and social burdens on individuals and their livelihoods. ${ }^{34}$ Like many other nations of the world, in response to the global pandemic, the Nigerian government established a Presidential Task Force for the Control of COVID-19, closed its borders, and mandated a national lockdown. ${ }^{3}$ While these measures have been effective in minimizing the spread of the disease, there is emerging consensus that the COVID-19 pandemic has caused significant disruption in the country's economic, social, and health care systems. ${ }^{3,6}$ Sex workers are among the vulnerable populations disproportionately affected by the COVID-19 pandemic globally.,11,17-20,35 To better understand how COVID-19 infection is affecting FCSW in the Niger Delta region of Nigeria, where this trade is pervasive, our team assessed their KAP, and potentials for community transmission of the SARS-CoV-2 virus.

More than half of the participants (66.4\%) indicated their willingness to stop sex work, if the government provides them with alternative means of livelihood. The implementation of lockdown and restrictions alongside concerns about COVID-19 infection caused sex workers to lose their source of income, and therefore, unable to provide for themselves and their families. Sex workers have largely been left out of Nigerian government's safety net programs forcing them to secretly continue to engage in sex work, and thus put themselves and others at greater risk of contracting COVID-19 with the potential to cause community transmission of SARS-CoV-2. For instance, majority of our study participants $(89.1 \%)$ indicated that they are not very familiar with all of the symptoms of COVID-19, do not know the hospital to go to (44.7\%) or the phone number to call for medical attention and testing (56.0\%). This implies that the Nigerian government and the various support agencies need to implement COVID19 awareness and prevention programs that are tailored specifically to the FCSW population, to ensure better adoption of COVID-19 prevention practices and to curb the spread of the disease in this group. Additionally, because commercial sex work is an occupation that involves in-person meeting with different individuals daily with no social distancing, FCSW are at a high risk of contracting COVID-19 infection and could potentially serve as reservoirs for community transmission. Therefore, it is worthwhile for the government to include FCSW in the priority group for the COVID-19 vaccination program.

It is a well-established fact that the health and wellbeing of sex workers is inextricably linked to the health and well-being of their clienteles and to the broader public. ${ }^{36}$ Also, sex workers who engage in transactional sex may experience negative health consequences including an increased risk of HIV and other sexually transmitted infections or sexual and gender-based violence and mental health concerns. ${ }^{37}$ Therefore, it is important for the governments to include every citizen including vulnerable populations such as sex workers in their response efforts against the COVID-19 infection, especially as no one is safe, until everyone is safe. ${ }^{20,38}$ COVID-19 knowledge and awareness among FCSW was classified as good (74\%) and improved significantly with age and experience in sex work. It is likely that younger and less experienced FCSW may have been more interested in financial gains and less health and safety conscious. This may lead them to engage in risk-taking behaviors, which may in turn affect their acquisition of knowledge, and general awareness about COVID-19 pandemic. Our finding is similar to that obtained for the general population in Nigeria ${ }^{39,40}$ and in other African countries. ${ }^{28,41}$ However, it is expected that more people including sex workers may have become more knowledgeable over time due to increased exposure to COVID-19 information during and after the lockdown period.

Overall, almost three quarters of the participants had both good knowledge and awareness about COVID-19 but less than half of them $(41.1 \%)$ implemented good practice to prevent the spread of the disease. These results suggest that there are still gaps between the acquisition of knowledge, awareness, and the transformation into preventive practice. This phenomenon was also reported in crosssectional studies of COVID-19 knowledge, attitude and practice in the general public in Nigeria and other countries. ${ }^{39-44}$ Although the characteristics of the study populations and methodological approach differed from our current study, the variations in the outcomes highlight the fact that good knowledge and awareness might not necessarily translate to good prevention practices due to other underlaying factors such as geography, culture, belief and structural context. Consequently, more efforts are warranted to explore the relationship pathways of these measures and other possible factors influencing behavioral change, especially as these are essential to enhance the 
strategies required to manage and control COVID-19 infection among sex workers. While the current universal prevention approach requires adoption of social distancing and other protective measures, the nature of sex work make practical observation of these measures impossible, thereby further compromising COVID-19 response. ${ }^{19,38}$ Odigie et al in their recent study recommended some measures for mitigating the activities of sex workers to reduce the spread of SARS-CoV-2 that include provision of behavioral interventions, supportive legislation, policy and funding for sex workers among others. ${ }^{38}$

FCSW who had many years of experience in sex work and encountered 3 or more clients daily had good awareness, were more conscious of their safety and reported taking good protective measures such as avoiding kissing their partners (56.2\%). However, only $10.9 \%$ indicated that they wore facemask at all times while $45.2 \%$ do not wear facemask during sexual encounter with their clienteles. Participants' decisions to implement these protective measures seemed to have been motivated by wanting to reduce their risk of COVID-19 infection, which may result in serious illness. Several studies support the use of facemasks to provide source control and reduce transmission in the community. ${ }^{45-49}$ The risk of transmission after contact with an individual with COVID-19 increases with the closeness and duration of contact and appears highest with prolonged contact in indoor settings. ${ }^{50}$ It is possible that many of the FCSW were still hesitant to act on their risk perceptions and preferred taking "a wait and see approach"- perhaps because social distancing can be perceived as difficult and costly. ${ }^{51}$ To promote protective behaviors among this vulnerable population, it may be necessary to address risks, as well as other factors that have been deemed relevant to behavior change, such as the perceived chance of infecting others, social norms, ability to implement protective behaviors and bear any associated costs, ${ }^{34,51-54}$ or the perceived need to follow public health recommendations and stay-at-home orders.

COVID-19 KAP among FCSW varied significantly $(p<0.0001)$ by marital status, age group, habit, number of sex clients per day and years of experience in commercial sex work. Similar variations in KAP measures have been reported in numerous subpopulations in different countries. ${ }^{39-44}$ Surprisingly, FCSW who indulged in habits such as drinking alcohol, smoking cigarettes and taking drugs had significantly $(p<0.0001)$ better COVID-19 preventive practices than those who exhibited no such habits. According to theories of decisions about health behavior, people who perceive greater risks are more motivated to implement protective behaviors. ${ }^{34,51,55}$ Our study finding thus supports the assertion by Bruine de Bruin and Bennett that assessing associations between risk perceptions and protective behaviors have practical and theoretical relevance. $^{51}$

COVID-19 knowledge and awareness among FCSW were significant and positively correlated with COVID-19 preventive practices and predicted $81.2 \%$ and $73.7 \%$, respectively, of the associated variations in protective measure against SARS-CoV-2. This implied that individuals with high knowledge and awareness scores demonstrate a more positive perception and practice more preventive measures. ${ }^{4,56}$ Following the heterogeneity of the FCSW in the Niger Delta Region of Nigeria, we identified the density contours and ellipses of the bivariate measures at different probabilities (Figures 1-3) that showed the intersections between COVID-19 KAP. Furthermore, our study used the LCA to systematically classify the attributes and behaviors of FCSW into three distinct clusters or risk groups, namely, the low-risk takers, high-risk takers, and very high-risk takers with prevalence rates of $41.13 \%$, $33.17 \%$ and $25.71 \%$, respectively. These various risk classifications can be used as the basis for the development of a unique and targeted interventions for each homogenous group to improve COVID-19 KAP among sex workers in the Niger Delta region of Nigeria. Nonetheless, some researchers have indicated that vulnerability to the COVID-19 pandemic cannot be fully explained by individual risks alone but rather by broader social and structural determinants of health that result in inequities in communities where vulnerable populations live, work, play, pray, and learn. ${ }^{57-59}$

\section{Implication of Study Findings}

In order to improve the public health outcomes and avoid potential community transmission of COVID-19 disease, the government must be willing to serve the needs of all people, including sex workers. Sex workers in Nigeria and Uganda have reported that their exclusion from government safety net had forced them to go back to sex work amid COVID-19. ${ }^{38,60}$ However, in Nigeria, like many other African countries, commercial sex work is illegal and a criminal offense. To prevent and control COVID-19 infection in this vulnerable population, it is essential for the government and public health authorities to work with sex workers union or the representatives of sex workers networks to develop guidelines and intervention programs 
that could range from altering sexual practices, provision of educational resources, sanitizers, facemasks, personal protective equipment to COVID-19 testing, management and contact tracing. Such collaborative efforts will ensure collective and inclusive response in the fight against COVID-19, especially as all people deserve to feel safe when accessing resources for health promotion and disease prevention. ${ }^{11,20}$ Public health messaging and dissemination of educational materials to the general public, should in addition, be targeted specifically towards vulnerable populations such as sex workers who by the nature of their trade, and as supported by our current study findings are most at high-risk of contracting the COVID-19 disease and spreading it in the community. Research efforts are needed to draw from the real-life experiences of FCSW during COVID-19 pandemic. Such evidence-based data could be used to develop public health intervention strategies specific to this high-risk population and to scale-up the level of preparedness for future emerging infectious and contagious diseases.

\section{Study Limitations and Strengths}

The findings from our study should be interpreted with some important limitations in mind. First, our study was a crosssectional study conducted using a random sample of hotels, brothels, bars and club houses in the Niger Delta region of Nigeria. There is the possibility that some establishments in the interior areas or villages within the region may have been excluded in the sample. This may cause sampling bias and the likelihood of overestimation of the strength of some of the associations. Although the generalizability of our findings is limited to the region, definite causality cannot be inferred. Second, because behaviors were self-reported, our results are subjected to potential response biases such as recall and social desirability bias. Also, response bias may emanate from the administration of the questionnaire by both trained research assistants and representatives of some participating establishments who received just-in-time training to assist the research team with survey administration due to the uncooperative nature of some FCSW. Third, our study was carried out in May-July 2020, and thus, the current outcomes may have changed slightly over time due to the dynamic nature of COVID-19 pandemic, warranting the need for longitudinal studies.

The strength of this study lies in the large sample size of this "hidden" population that was recruited in the Niger Delta region where sex work is prevalent, especially during the government lockdown orders and early stage of the
COVID-19 pandemic. In addition, our study systematically classified the FCSW into three distinct homogenous groups (low-risk takers, high-risk takers and very high-risk takers), based on their attributes and behaviors, which could be used for targeted interventions aimed at improving their COVID-19 KAP. While the risk perceptions among the sex workers do not represent that of the general public in the Niger Delta region of Nigeria, the strengths of this study are its ability to produce culturally competent and context-specific risk scenarios that may be used as basis for the COVID-19 response efforts in this vulnerable population. Understanding the relationship of knowledge, attitude, and practice towards the COVID-19 pandemic is significant and essential to enhance the strategies required to manage and control this pandemic. ${ }^{42}$

\section{Conclusion}

In summary, our study findings indicate that while almost three quarters of FCSW in the Niger Delta region of Nigeria have good knowledge and awareness about COVID-19, less than half of them $(41.1 \%)$ implemented good practice to prevent the spread of the disease in the community. The low rate of adoption of preventive practice may lead to poor infection control and spread of the SARS-CoV-2, warranting targeted interventions for the risk groups identified in our study. Since the clinical presentation of COVID-19 is mainly symptomatic, it is clear that good KAP against the disease are vital for the management and control of the pandemic. While we cannot rely solely on identifying and isolating symptomatic cases, strategic testing of high-risk groups such as FCSW, who may be asymptomatic yet continue to provide sexual services to variety of clienteles, may help reduce community transmission risk and control SARS-CoV-2. More resources are therefore needed to protect individuals who engage in sex work during the COVID-19 pandemic, especially because of the role they may play in serving as reservoirs for community transmission of the disease, if risk reduction strategies are not implemented. Longitudinal studies are needed to understand how knowledge, awareness, risk perceptions, protective behaviors, and their associations changed over time beyond the early stages of the COVID-19 pandemic.

\section{Author Contributions}

All authors made substantial contributions to conception and design, acquisition of data, or analysis and interpretation of data; took part in drafting the article or revising it critically for important intellectual content; agreed to 
submit the article to the current journal; gave final approval of the version to be published; and agreed to be accountable for all aspects of the work.

\section{Funding}

This research received no specific grant from any funding agency in the public, commercial, or not-for-profit sectors.

\section{Disclosure}

No conflict of interest has been declared by the authors.

\section{References}

1. World Health Organization. Coronavirus Disease Dashboard. Available from https://covid19.who.int/. Accessed April 12, 2021.

2. Africa Centers for Disease Control and Prevention. Latest updates on the COVID-19 crisis from Africa CDC. Available from https://afri cacdc.org/covid-19/. Accessed April 12, 2021.

3. Chukwuorji JC, Iorfa SK. Commentary on the Coronavirus Pandemic: nigeria. Psychol Trauma. 2020;12(S1):S188- S190. doi: $10.1037 /$ tra0000786

4. Ajibo H. Effect of COVID-19 on Nigerian socio-economic well-being, health sector pandemic preparedness and the role of Nigerian social workers in the war against COVID-19. Soc Work Public Health. 2020;35(7):511-522. doi:10.1080/ 19371918.2020.1806168

5. Andam K, Edeh H, Oboh V, Pauw K, Thurlow J. Impacts of COVID-19 on food systems and poverty in Nigeria. Adv Food Secur and Sustainability. 2020;2020(5):145-173.

6. Ajide KB, Ibrahim RL, Alimi OY. Estimating the impacts of lockdown on Covid-19 cases in Nigeria. TRIP. 2020;7:100217. doi:10.1016/j.trip.2020.100217

7. Kimani J, Adhiambo J, Kasiba R, et al. The effects of COVID-19 on the health and socio-economic security of sex workers in Nairobi, Kenya: emerging intersections with HIV. Glob Public Health. 2020;15(7):1073-1082. doi:10.1080/17441692.2020.1770831

8. Frances NN, Pegg S. Socially distanced school-based nutrition program under COVID-19 in the rural Niger Delta. Extr Ind Soc. 2020;7 (2):576-579. doi:10.1016/j.exis.2020.04.007

9. Odigie BE. Role of histology-medical laboratory scientists in maintaining the sexual gates of female sex workers in Nigeria. CentrePoint J. 2017;23(1):41-52.

10. David UJ, Poroma C, Jackson OR. Oil economy and female prostitution in Port Harcourt. Int Lett Soc Humanist Sci. 2015;42:121-132.

11. Singer R, Crooks N, Johnson A, Lutnick A, Mathews A. COVID-19 prevention and protecting sex workers: a call to action. Arch Sex Health. 2020;49:2739-2741.

12. Human Rights Campaign. The lives and livelihoods of many in the LGBTQ community are at risk amid COVID-19 crisis (No. COVID19-IssueBrief-032020); 2020. Available from: https:// assets2.hrc.org/files/assets/resources/COVID19-IssueBrief-032020FINAL.pdf?_ga=2.245594500.1637528607.1596592484-720055857. 1596592484. Accessed April 12, 2021.

13. Platt L, Elmes J, Stevenson L, Holt V, Rolles S, Stuart R. Sex workers must not be forgotten in the COVID-19 response. Lancet. 2020;396(10243):9-11. doi:10.1016/S0140-6736(20)31033-3

14. NUM. Evidence submitted by national ugly mugs (CVG0014). Women and Equality Committee Website; 2020. Available from: https://committees.parliament.uk/writtenevidence/8610/pdf/. Accessed April 10, 2021.
15. Mastrocola EL, Taylor AK, Chew-Graham C. Access to healthcare for long-term conditions in women involved in street-based prostitution: a qualitative study. BMC Fam Pract. 2015;16(1):118. doi:10.1186/s12875-015-0331-9.26338724

16. Janyam S, Phuengsamran D, Pangnongyang J, et al. Protecting sex workers in Thailand during the COVID-19 pandemic: opportunities to build back better. WHO South East Asia J Public Health. 2020;9 (2):100-103. doi:10.4103/2224-3151.294301

17. Howard S. COVID-19: health needs of sex workers are being sidelined, warn agencies. BMJ. 2020;369:m1867. doi:10.1136/bmj. m1867

18. Jozaghi E, Bird L. COVID-19 and sex workers: human rights, the struggle for safety and minimum income. Can J Public Health. 2020;111(3):406-407. doi:10.17269/s41997-020-00350-1

19. Karlis N Sex workers are stressed, anxious and depressed amid COVID-19 pandemic. Salon; 22 March 2020. Available from: https://www.salon.com/2020/03/22/sex-workers-are-stressed -anxious-and-depressed-amid-covid-19-pandemic/. Accessed July 7, 2020.

20. Adebisi YA, Alaran AJ, Akinokun RT, Micheal AI, Ilesanmi EB, Lucer-Prisno DE. Sex workers should not be forgotten in Africa's COVID-19 response. Am J Trop Med Hyg. 2020;103(5):1780-1782. doi:10.4269/ajtmh.20-1045

21. Shannon K, Crago A, Baral S, Bekker L, Kerrigan D, Decker M. The global response and unmet actions for HIV and sex workers. Lancet. 2018;392(10148):698-710. doi:10.1016/S0140-6736(18)31439-9

22. Ngwewondo A, Nkengazong L, Ambe L, et al. Knowledge, attitudes, practices of/towards COVID-19 preventive measures and symptoms: a cross-sectional study during the exponential rise of the outbreak in Cameroon. PLoS Negl Trop Dis. 2020;14(9):e0008700. doi:10.1371/ journal.pntd.0008700.

23. Overs C. Sex Workers: part of the Solution - An analysis of HIV prevention programming to prevent HIV transmission during commercial sex in developing countries; 2002. 42 pp. Available from: https://www.who.int/hiv/topics/vct/sw.toolkit/115solution.pdf. Accessed September 7, 2020.

24. NPC: National Population Census 2006. Federal Republic of Nigeria: Federal Ministry of Women and Social Development.

25. Akoroda M. Remediation Response in the Niger Delta. Paper Presented at a Seminar to Market Then Anniversary of Jesse Fire Disaster. Lagos: Nigeria Institute of International Affairs; 2000.

26. Ike PC, Emaziye PO. An assessment of the trend and projected future values of climatic variables in Niger Delta Region, Nigeria. Asian J Agric Res. 2012;4(2):165-170.

27. Nigeria Centre for Disease Control (NCDC). Coronavirus (COVID-19) Guidelines. Available from: https://covid19.ncdc.gov. ng/guideline/. Accessed September 7, 2020.

28. Abdelhafiz AS, Mohammed Z, Ibrahim ME, et al. Knowledge, perceptions, and attitude of Egyptians towards the novel Coronavirus Disease (COVID-19). J Community Health. 2020;45(5):881-890. doi:10.1007/s10900-020-00827-7.

29. Zhang M, Zhou M, Tang F, et al. Knowledge, attitude, and practice regarding COVID-19 among healthcare workers in Henan, China. J Hosp Infect. 2020;105(2):183-187. doi:10.1016/j.jhin.2020.04.012.

30. Zhong BL, Luo W, Li HM, et al. Knowledge, attitudes, and practices towards COVID-19 among Chinese residents during the rapid rise period of the COVID-19 outbreak: a quick online cross-sectional survey. Int $J$ Biol Sci. 2020;16(10):1745-1752. doi:10.7150/ ijbs.45221.

31. Vermunt JK, Magidson J. "Latent class cluster analysis". In: Hagenaars J, Mccutcheon A, editors. Applied Latent Class Analysis. Cambridge: Cambridge University Press; 2002:89-106.

32. Borman S. The Expectation Maximization Algorithm: a short tutorial; July 18, 2004. Available from: https://www.lri.fr/ sebag/ COURS/EM_algorithm.pdf. Accessed December 20, 2020. 
33. Cucinotta D, Vanelli M. WHO declares COVID-19 a pandemic. Acta Biomed. 2020;91(1):157-160. doi:10.23750/abm.v91i1.9397

34. Bavel JJV, Baicker K, Boggio PS, et al. Using Social and Behavioral Science to support COVID-19 pandemic response. Nat Hum Behav. 2020;4(5):460-471. doi:10.1038/s41562-020-0884-z.

35. Passos TS, Almeida-Santos MA. Trabalho sexual em período de pandemia por COVID-19 no contexto íbero-americano: análise de anúncios em websites [Sex Work during the COVID-19 pandemic period in the Ibero-American Context: analysis of advertisements on websites]. Cien Saude Colet. 2020;25(11):4237-4248. doi:10.1590/ 1413-812320202511.26622020.

36. Patterson TL, Goldenberg S, Gallardo M, et al. Correlates of HIV, sexually transmitted infections, and associated high-risk behaviors among male clients of female sex workers in Tijuana, Mexico. AIDS. 2009;23(13):1765-1771. doi:10.1097/QAD.0b013e32832f08a1

37. Meeting Targets and Maintaining Epidemic Control (EpiC). Strategic considerations for mitigating the impact of COVID-19 on key-HIV programs [Internet]. FHI 360; 2020 May [cited January 16, 2021]. 16 p. Available from: https://www.unaids.org/sites/default/files/media_asset/ kp-strategic-considerations-covid19_en.pdf. Accessed May 3, 2021.

38. Odigie EB, Airiagbonbu BO, Adegboye AA. Escapades of Sex workers amidst lockdown: an untold navigation pathway for SARS-CoV-2 Community transmission in Nigeria. J Med Lab Sci. 2020;30(2):99-109.

39. Olapegba PO, Ayandele O, Kolawole SO, et al. A preliminary assessment of novel coronavirus (COVID-19) knowledge and perceptions in Nigeria. Soc Sci Hum Open. 2020. doi:10.2139/ssrn.3584408.

40. Shehu H, Rao PD. Sociology of Covid-19: people perceptions regarding the outbreak of the pandemic among people of Northern, Nigeria. Sustain. Humanosphere. 2020;16(1):2078-2089.

41. Austrian K, Pinchoff J, Tidwell JB, et al. COVID-19 related knowledge, attitudes, practices and needs of households in informal settlements in Nairobi, Kenya. Lancet Glob Health. 2020;2020. doi:10.2139/ ssrn.3576785.

42. Yang K, Liu H, Ma L, et al. Knowledge, attitude and practice of residents in the prevention and control of COVID-19: an online questionnaire survey [published online ahead of print, 2020 Dec 1]. $J$ Adv Nurs. 2020. doi:10.1111/jan.14718

43. Iloanusi NR, Iloanusi S, Mgbere O, Ajayi A, Essien EJ. COVID-19 related knowledge, attitude and practices in a Southeastern City in Nigeria: a cross-sectional survey; 2020. doi:10.2139/ssrn.3683766

44. Wake AD. Knowledge, attitude, practice, and associated factors regarding the novel coronavirus disease 2019 (COVID-19) pandemic. Infect Drug Resist. 2020;13:3817-3832. doi:10.2147/ IDR.S275689.

45. Clase CM, Fu EL, Joseph M, et al. Cloth masks may prevent transmission of COVID-19: an evidence-based, risk-based approach. Ann Intern Med. 2020;173(6):489. doi:10.7326/M20-2567

46. Leung NHL, Chu DKW, Shiu EYC, et al. Respiratory virus shedding in exhaled breath and efficacy of face masks. Nat Med. 2020;26 (5):676. doi:10.1038/s41591-020-0843-2

47. Liang M, Gao L, Cheng C, et al. Efficacy of face mask in preventing respiratory virus transmission: a systematic review and meta-analysis. Travel Med Infect Dis. 2020;36:101751. doi:10.1016/j. tmaid.2020.101751

International Journal of Women's Health

\section{Publish your work in this journal}

The International Journal of Women's Health is an international, peerreviewed open-access journal publishing original research, reports, editorials, reviews and commentaries on all aspects of women's healthcare including gynecology, obstetrics, and breast cancer. The
48. Chu DK, Akl EA, Duda S, et al. Physical distancing, face masks, and eye protection to prevent person-to-person transmission of SARS-CoV-2 and COVID-19: a systematic review and meta-analysis. Lancet. 2020;395(10242):1973. doi:10.1016/S01406736(20)31142-9

49. Rader B, White LF, Burns MR, et al. Mask-wearing and control of SARS-CoV-2 transmission in the USA: a cross-sectional study. Lancet Digit Health. 2021;3(3):e148. doi:10.1016/S2589-7500(20) 30293-4

50. McIntosh K, Hirsch MS, Bloom A. COVID-19: epidemiology, virology, and prevention. UpToDate; Topic 126981 Version 141.0. Available from: https://www.uptodate.com/contents/covid-19epidemiology-virology-and-prevention. Accessed April 12, 2021.

51. Bruine de Bruin W, Bennett D. Relationships between initial COVID-19 risk perceptions and protective health behaviors: a national survey. Am J Prev Med. 2020;59(2):157-167. doi:10.1016/j.amepre.2020.05.001.

52. Fischhoff B. Risk perception and communication. In: Fischhoff B, editor. Risk Analysis and Human Behavior. UK: Routledge; 2012:3-32. doi:10.4324/9780203140710.

53. Rosenstock IM. The health belief model and preventive health behavior. Health Educ Monogr. 1974;2(4):354-386. doi:10.1177/ 109019817400200405.

54. Slovic P, Finucane ML, Peters E, MacGregor DG. Risk as analysis and risk as feelings: some thoughts about affect, reason, risk, and rationality. Risk Anal. 2004;24(2):311-322. doi:10.1111/j.02724332.2004.00433.x

55. Gbagbo FY. Experiences of commercial sex workers during COVID-19 restrictions in selected metropolises in Ghana [published online ahead of print, 2020 Oct 1]. Health Care Women Int. 2020;1-12. doi:10.1080/07399332.2020.1822362.

56. Papagiannis D, Malli F, Raptis DG, et al. Assessment of knowledge, attitudes, and practices towards new coronavirus (SARS-CoV-2) of health care professionals in Greece before the outbreak period. Int J Environ Res Public Health. 2020;17(14):4925. doi:10.3390/ ijerph1714492540.

57. Palmer RC, Ismond D, Rodriquez EJ, Kaufman JS. Social determinants of health: future directions for health disparities research. $A m$ $J$ Public Health. 2019;109(S1):S70-1. doi:10.2105/ AJPH.2019.304964

58. Williams DR, Lawrence JA, Davis BA. Racism and health: evidence and needed research. Annu Rev Public Health. 2019;40(1):105-125. doi:10.1146/annurev-publhealth-040218-043750

59. Brown AF, Ma GX, Miranda J, et al. Structural interventions to reduce and eliminate health disparities. Am J Public Health. 2019;109(S1):S72-8. doi:10.2105/AJPH.2018.304844

60. BBC News. Coronavirus: how sex workers are surviving in Uganda and Nigeria. BBC News; 2020. Available from: https://www.bbc. com/news/av/world-africa-53013047/coronavirus-how-sex-workersare-surviving-in-uganda-and-nigeria. Accessed January 16, 2021. manuscript management system is completely online and includes a very quick and fair peer-review system, which is all easy to use. Visit http://www.dovepress.com/testimonials.php to read real quotes from published authors. 